\title{
PERSEPSI PENGELOLA HOTEL BINTANG 1-5 \\ TERHADAP FUNGSI DAN FITUR MEDIA PEMASARAN ONLINE DI KECAMATAN KUTA, PROVINSI BALI
}

\author{
Bagus Putu Wahyu Nirmala \\ Universitas Udayana, STMIK Primakara Denpasar
}

\begin{abstract}
This study aims to determine the online media that are used by star hotel managers in Kuta and analyze their perception of its features and functions. The study shows that there are seven online media are widely used by hotel managers: search engine, e-mail, website, twitter.com, facebook.com, OTA and tripadvisor.com. There are five digital marketing functions: attract, engage, retain, learn and relate. More digital marketing functions that can be produced by online media more likely to be used. Average calculation of respondents' perception obtained 4.08 that indicates the features of online media have considered beneficial for marketing functions. The features that considered as the most helpful are regularly content updating (4.60 of 5.00), online media registration on search engines (4.51 of 5.00), and making unique content (4.40 of 5.00). Factor analysis shows that each feature has various benefits for function of digital marketing. The features considered the most helpful are online media registration on search engines (to attract), build virtual community (to engage), using cookies to identify IP address (to learn), personalized communication (to relate). The features considered the most helpful for retaining are interactive applications and regularly content updating.
\end{abstract}

Keywords: perception, hotel manager, Kuta, features, functions, online media, marketing tool, digital marketing framework.

\begin{abstract}
Abstrak
Penelitian ini bertujuan untuk mengetahui media online yang digunakan oleh manajer hotel bintang di Kuta dan menganalisis persepsi mereka tentang fitur media online dan fungsi. Setelah melakukan pengumpulan data dan analisis terdapat tujuh media online yang banyak digunakan oleh manajer hotel.
\end{abstract}


Mereka adalah mesin pencari, e-mail, website, twitter.com, facebook.com, OTA dan tripadvisor.com. Ada lima fungsi pemasaran digital: attract, engage, retain, learn dan relate. Semakin banyak fungsi pemasaran digital yang dapat dihasilkan oleh media online lebih mungkin media online tersebut untuk digunakan. Rata-rata perhitungan persepsi responden diperoleh 4,08 yang menunjukkan bahwa fitur media online telah dianggap bermanfaat untuk fungsi pemasaran. Fitur yang dianggap sebagai yang paling bermanfaat memperbarui secara teratur konten(4.60 dari 5.00), pendaftaran media online di search engine $(4,51$ dari 5,00$)$, dan membuat konten yang unik (4.40 dari 5.00). Analisis faktor menunjukkan bahwa setiap fitur memiliki berbagai manfaat untuk fungsi pemasaran digital. Fitur dianggap paling membantu adalah pendaftaran media online di search engine (untuk attract), membangun komunitas virtual (untuk engage), menggunakan cookies untuk mengidentifikasi alamat IP (untuk learn), komunikasi pribadi (untuk relate). Fitur dianggap paling bermanfaat untuk mempertahankan aplikasi interaktif dan memperbarui secara teratur konten.

Kata kunci: $\quad$ persepsi, manajer hotel, Kuta, fitur, fungsi, media online, alat pemasaran, kerangka pemasaran digital.

\section{Pendahuluan}

UNWTO (2015:2) menyatakan bahwa selama enam dekade, industri pariwisata telah berkembang menjadi salah satu sektor ekonomi terbesar dengan pertumbuhan paling cepat. Jumlah kedatangan wisatawan di seluruh dunia pada tahun 2014 adalah 1,13 milyar dan diprediksi mencapai 1,8 milyar pada tahun 2030 (UNWTO, 2015: 2). Selama enam dekade tersebut, industri pariwisata mengalami dinamika. Saat ini ada tiga kondisi yang sedang dihadapi oleh industri ini yaitu (1) besarnya pengaruh internet, (2) meningkatnya jumlah akomodasi dan (3) ketatnya persaingan di dunia online. Kondisi ini terutama dirasakan di Kecamatan Kuta, Provinsi Bali sebagai sebuah destinasi internasional.

Kondisi pertama yang dihadapi industri pariwisata di Kuta dan Bali pada umumnya adalah besarnya pengaruh internet. Pengaruh internet tersebut dapat dipahami dari data dan informasi industri pariwisata. Menurut statisticbrain. com selama tahun 2012 nilai penjualan travel online mencapai angka USD 162,4 miliar. ${ }^{1}$ Selain itu, pada tahun 2013, pemanfaatan media online dalam memilih jasa akomodasi mencapai 83 persen dan 39 persen mengaksesnya dengan

1 http://www.statisticbrain.com/internet-travel-hotel-booking-statistics/ 
perangkat bergerak (mobile devices) (Singapore Tourism Board, 2013: 19). Per 3 April 2016 terdapat 8.669 properti / akomodasi dari Indonesia terdaftar di booking.com dan 54,3 persen diantaranya berlokasi di Bali. Di Kuta sendiri, adanya internet memungkinkan seluruh tahapan perencanaan dan kegiatan wisata dilakukan secara mandiri oleh wisatawan.

Kondisi kedua yang dihadapi industri pariwisata adalah peningkatan jumlah akomodasi di Kecamatan Kuta. Pertumbuhan akomodasi di Pulau Bali menunjukkan tren peningkatan yang positif secara kuantitas. Namun, PHRI Badung menyatakan jumlah akomodasi sudah over supply dan telah mengakibatkan kompetisi harga. ${ }^{2}$ Dinas Pariwisata Provinsi Bali (2016: 3) telah mencatat terdapat 154 hotel bintang 1-5 di Kabupaten Badung dengan total kamar mencapai 24.210 kamar. Angka ini belum termasuk akomodasi kecil seperti homestay dan akomodasi lain yang belum mengantongi izin.

Kondisi ketiga yang dihadapi industri pariwisata adalah ketatnya persaingan hotel di dunia online. Berdasarkan data Dinas Pariwisata Provinsi Bali (2016) di Kecamatan Kuta hanya terdapat 71 hotel bintang 1-5. Namun, facebook.com menampilkan 101 hasil pencarian untuk kata kunci "Kuta hotel". Bahkan google maps menampilkan 352 hasil pencarian untuk kata kunci "Kuta Hotel”. Kedua hasil pencarian tersebut mencakup hotel legal, hotel illegal, akomodasi lainnya dan usaha wisata bukan akomodasi. Hal ini menunjukkan persaingan yang terjadi sangat bebas dan tidak terkendali.

Tiga kondisi di atas mengharuskan pengelola hotel di Kecamatan Kuta khususnya bagian pemasaran melakukan usaha pemasaran ekstra. Bersaing dengan metode pemasaran konvensional seperti pameran, table top, dan travel fair masih dapat dilakukan. Namun efektivitas dan efisiensinya tentu perlu dikaji kembali agar sumber daya yang dimiliki hotel tidak terbuang percuma. Gede Gunawan (komunikasi personal, 2013) dari Agoda.com meminta industri tidak lagi mengandalkan metode pemasaran konvensional dan segera memanfaatkan media online seperti OTA agar dapat berkompetisi. Pihak hotel juga harus menyiapkan sumber daya baik sumber daya manusia maupun anggaran khusus untuk pemasaran dengan media online.

Ketiga kondisi di atas menunjukkan pengelola hotel makin dituntut cerdas dan kreatif oleh perkembangan teknologi. Pengelola hotel harus mulai memanfaatkan media online. Robbins (2013) menyatakan bahwa perilaku organisasi didasarkan pada persepsi terhadap informasi yang diterima. Jika manajemen hotel adalah sebuah organisasi maka pengelola hotel harus memiliki persepsi yang tepat terhadap fitur dan fungsi yang mampu dihasilkan oleh media online. Dalam studi awal penelitian ini diperoleh temuan beberapa pengelola hotel menyamakan search engine dengan Mozilla Firefox dan alamat website hotel. Selain itu, ada pengelola

2 BPC PHRI Badung. 2013. Tantangan Industri Jasa Pelayanan Akomodasi Di Tahun 2020. Diakses pada 21 Agustus 2014 dari http://ihrabadung.org/ 
hotel yang keliru membedakan social network dan social media. Persepsi yang keliru tersebut akan berdampak pada kekeliruan pemanfaatan media online sehingga menyebabkan usaha pemasaran yang dilakukan kurang efektif. Dengan demikian, persepsi yang keliru atau salah akan menurunkan kemampuan bersaing hotel yang bersangkutan sehingga akan menghambat pertumbuhan usaha itu sendiri.

Mengingat perkembangan teknologi informasi bersifat sangat dinamis. Teknologi yang saat ini menjadi kebutuhan dengan cepat dapat digantikan dengan teknologi lain yang lebih canggih. Pengelola hotel perlu mempelajari secara berkelanjutan mengenai media online dan mengetahui kunci sukses pemasaran digital. Persepsi yang tepat terhadap media online, fungsi beserta fiturnya akan mempengaruhi kinerja bagian pemasaran sehingga berdampak pada perkembangan usaha. Hal ini dapat memotivasi pengelola hotel dalam memahami media online. Selain itu, kerangka pemasaran digital oleh Kierzkowski et al (1996) dinilai sebagai kunci sukses pemasaran digital. Kerangka pemasaran digital terdiri atas lima komponen yang mampu menghasilkan fungsi media online yaitu attract, engage, retain, learn dan relate. Tiap fungsi ini terlaksana dari adanya fitur-fitur yang dimiliki media online. Sehingga semakin baik persepsi terhadap fitur dan fungsi media online, semakin paham fungsi yang bisa dicapai dan makin efektif usaha pemasaran hotel tersebut.

Persepsi pengelola hotel terhadap media online sebagai alat pemasaran menjadi semakin penting. Pengaruh perkembangan teknologi seperti media online makin besar. Pertumbuhan jumlah akomodasi menambah ketatnya persaingan. Baik akomodasi legal maupun ilegal memiliki kesempatan yang sama dalam memanfaatkan media online. Hal ini semakin memicu kompetisi harga. Pengelola hotel makin dituntut meningkatkan faktor kompetitifnya sehingga mendukung pertumbuhan usahanya dengan cara memanfaatkan media online.

Artikel ini ditulis berdasarkan penelitian persepsi pengelola hotel bintang 1-5 di Kecamatan Kuta terhadap fungsi dan fitur yang dimiliki media online sebagai alat pemasaran. Selain itu, penelitian ini juga bertujuan untuk mengetahui alasan penggunaan media online oleh pengelola hotel di Kecamatan Kuta. Artikel ini diharapkan dapat memberi gambaran bagi para pemangku kebijakan baik pengelola dan asosiasi industri dalam menentukan arah penguatan fungsi pemasaran melalui media online.

\section{Usaha Akomodasi di Kecamatan Kuta}

Kuta mulai dikenal sebagai destinasi wisata pada tahun 1960 sebagai tempat wisatawan menikmati sunset setelah menikmati wisata di Sanur. Kondisi ini mendorong masyarakat mendirikan jasa akomodasi berupa penginapan. Dari peningkatan jumlah kunjungan, pada tahun 1970 jumlah 
kunjungan sebanyak 1.000 orang, pada tahun 1973 jumlah kunjungan sebanyak 15.000 orang (Picard, 2006). Peningkatan tersebut mendorong makin banyaknya tumbuh usaha wisata seperti akomodasi, restoran, agen travel, butik dan lain-lain (Tabel 2.1).

Tabel 2.1 Kapasitas Kamar di Kecamatan Kuta

\begin{tabular}{ccc}
\hline No. & Tahun & Kapasitas Kamar \\
\hline 1. & 1976 & 1.500 \\
2. & 1981 & 2.900 \\
3. & 1994 & 17.600 \\
\hline
\end{tabular}

Sumber: Picard, 2006

Perkembangan pariwisata Kuta relatif masif dibandingkan Sanur, Nusa Dua dan Denpasar. Dinas Pariwisata Provinsi Bali (2016) mencatat terdapat 154 hotel bintang di Kabupaten Badung dengan total kapasitas 24.210 kamar. Data Dinas Pariwisata Provinsi Bali (2016) menunjukkan bahwa terdapat 71 hotel bintang 1-5 yang tersebar di lima kelurahan di Kecamatan Kuta (Tabel 2.2).

Tabel 2.2 Jumlah Hotel Bintang 1-5 di Kabupaten Badung Tahun 2011-2015

\begin{tabular}{cccccccccc}
\hline \multicolumn{2}{c}{2011} & \multicolumn{2}{c}{2012} & \multicolumn{2}{c}{2013} & \multicolumn{2}{c}{2014} & \multicolumn{2}{c}{2015} \\
\hline Hotel & Kamar & Hotel & Kamar & Hotel & Kamar & Hotel & Kamar & Hotel & Kamar \\
\hline 100 & 16021 & 98 & 15652 & 144 & 16820 & 154 & 24210 & 154 & 24210 \\
& & $\begin{array}{c}\text { Berkembang -2,3 } \\
\text { persen }\end{array}$ & $\begin{array}{c}\text { Berkembang 7,5 } \\
\text { persen }\end{array}$ & $\begin{array}{c}\text { Berkembang 43,9 } \\
\text { persen }\end{array}$ & $\begin{array}{c}\text { Berkembang } \\
\text { o persen }\end{array}$ \\
\hline
\end{tabular}

Sumber: Direktori 2015 Disparda Provinsi Bali, 2016

\section{Pemasaran Dengan Media Online}

Menurut Kotler (2010: 480) salah satu jenis pemasaran langsung adalah pemasaran langsung digital. Pemasaran langsung digital dapat dikelompokkan menjadi 2 bagian, yaitu pemasaran tanpa memanfaatkan internet dan pemasaran yang memanfaatkan teknologi internet seperti search engine, website, e-mail dan media sosial. Media pemasaran yang menggunakan internet ini kemudian dikenal dengan media online. Media sosial yang merupakan salah satu media online mengalami perkembangan yang dinamis selama satu dasawarsa ini. Banyaknya media sosial ini oleh Zarrella (2010) dibagi menjadi delapan kelompok yaitu: (1) blog; (2) microblog; (3)jejaring sosial; (4) media sharing; (5) social bookmarking; (6) review sites; (7) online forum; dan (8) virtual world (Tabel 3.1).

Pemasaran hotel menurut Ritherford dalam Yoeti (1999:9) adalah aktivitas yang menggunakan strategi dan taktik yang direncanakan sedemikian rupa untuk menyampaikan "cerita" tentang pelayanan yang mampu diberikan oleh suatu hotel dan mendorong/mempengaruhi wisatawan untuk mau 
Tabel 3.1 Ragam Media Sosial Berdasarkan Kelompoknya

\begin{tabular}{rll}
\hline No. & \multicolumn{1}{c}{ Kelompok } & \multicolumn{1}{c}{ Media Sosial } \\
\hline 1. & Blog & Wordpress.com, blogspot.com \\
2. & Microblog & Twitter.com \\
3. & Jejaring sosial & Facebook.com, plus.google.com, linkedin.com \\
4. & Media berbagi & Youtube.com, flickr.com, instagram.com, snapchat.com \\
5. & Social bookmark & Digg, reddit, stumbleupon, delicious \\
6. & Review site & Tripadvisor.com \\
7. & Online forum & Kaskus.com \\
8. & Virtual World & Secondlife, virtual tour \\
\hline
\end{tabular}

Sumber:Hasil Pengolahan Data, 2015

memilih berdasarkan pesan hotel tersebut dibandingkan pesaingnya. Media online dibutuhkan sebagai media promosi dan pemasaran oleh berbagai macam industri termasuk industri pariwisata khususnya hotel. Keberhasilan pemasaran hotel menggunakan media online dipengaruhi ketepatan dalam pemanfaatannya. Tiap media online memiliki fungsi yang berbeda-beda. Hal ini harus dipahami agar pemanfaatan media online menjadi efektif. Ada media online yang sangat baik digunakan untuk menarik (attract) pengunjung, mempertahankan (retain) kunjungan atau untuk memperoleh keterlibatan (engage) pengunjung dan sebagainya. Sebuah media online yang dilengkapi berbagai fitur dapat melaksanakan lebih dari satu fungsi.

Sebuah kerangka pemasaran digital (digital marketing framework) yang dikembangkan oleh Kierzkowski et al (1996) menunjukkan 5 macam fungsi yang mampu dihasilkan oleh media digital seperti media online yaitu attract, engage, retain, learn dan relate (Gambar 3.1). Fungsi-fungsi tersebut dapat dicapai karena fitur-fitur yang dimiliki. Berdasarkan Kierzkowski et al (1996) dan Teo dan Tan (2002), kerangka pemasaran digital terdiri dari:

a. Attract yang berarti menarik wisatawan agar mengunjungi media online yang dimiliki hotel. Untuk dapat menarik kunjungan, pengelola hotel memanfaatkan fitur-fitur seperti digital ads, registrasi di mesin pencarian, mnemonic branding, program afiliasi dan sebagainya.

b. Engage yang berarti mengikutsertakan wisatawan menggunakan media online hotel dan merupakan kelanjutan dari fungsi attract. Setelah terjadi kunjungan, diharapkan keterlibatan dan interaksi pengunjung di media online yang dikelola hotel. Untuk fungsi engage, pengelola hotel memanfaatkan fitur-fitur seperti content space, online payment, komunitas virtual, kontes atau kompetisi online, fitur multi-bahasa dan sebagainya. Perlu digarisbawahi agar content menghasilkan interaksi, content tersebut harus unik dan bermanfaat bagi pengunjung.

c. Retain yang berarti mempertahankan kunjungan. Sebuah hotel sebaiknya berusaha mempertahankan kunjungan online. Untuk 
mempertahankan kunjungan, pengelola sebaiknya meningkatkan keamanan media online-nya, memperbaharui content secara berkala, mengadakan program promosi dan sebagainya.

d. Learn yang berarti mempelajari lebih lanjut mengenai data kunjungan di media online. Data yang mungkin diperoleh adalah demografi pengunjung, perilakunya selama memanfaatkan media online dan sebagainya. Data ini bisa diperoleh dengan melakukan survei online, penyebaran formulir secara online, website page tracking, IP address tracking dan sebagainya.

e. Relate yang berarti membangun hubungan dengan wisatawan atau pengunjung. Informasi yang diperoleh pada tahap learn dilanjutkan dengan penciptaan nilai (value) bagi pengunjung agar tercipta hubungan jangka panjang. Beberapa hal yang dapat dilakukan dengan media online adalah penyediaan produk layanan yang disesuaikan saran atau permintaan pelanggan, online customer support, komunikasi yang dipersonalisasi sesuai dengan bahasa pelanggan dan sebagainya.

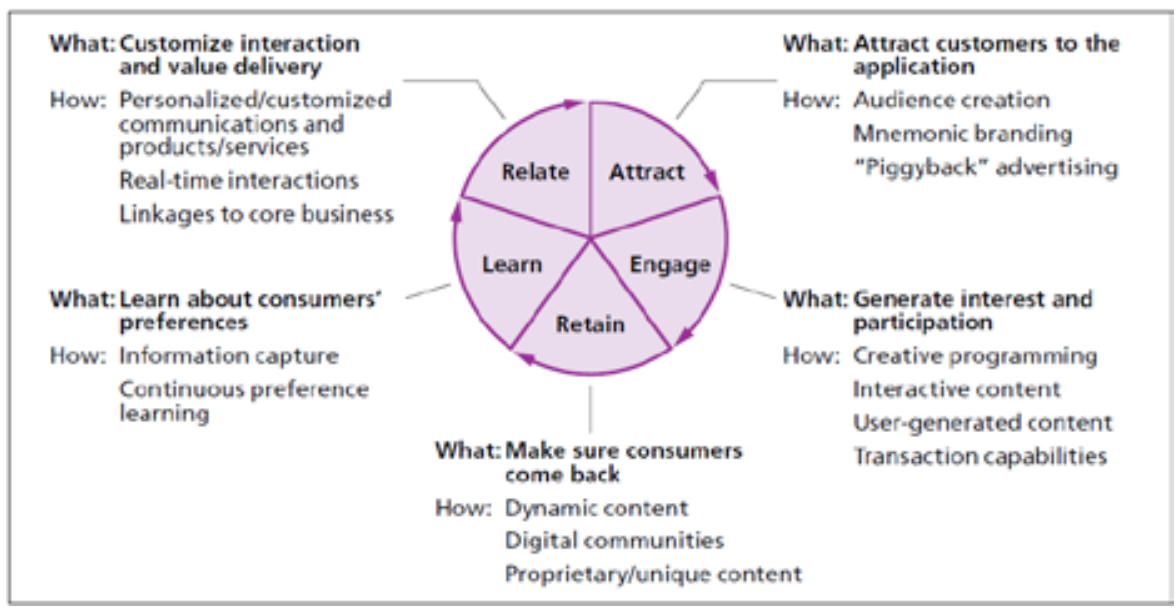

Gambar 3.1 Kerangka Pemasaran Digital

KIERZKOWSKI ET AL, 1996

\section{Metode Penelitian}

Metode penelitian yang digunakan adalah mix method. Hasil yang diperoleh bertujuan menggambarkan suatu keadaan yang sedang terjadi. Ada beberapa instrumen yang digunakan seperti kuesioner, observasi, panduan wawancara, voice recorder, dan kamera. Data yang diperoleh akan diolah. Data kuesioner akan dianalisis secara statistik. Informasi yang diperoleh dari hasil wawancara dan observasi digunakan untuk mempertajam hasil analisis. Penelitian dilakukan di Kecamatan Kuta, Provinsi Bali dari bulan Maret 2015 
hingga Desember 2015. Sampel penelitian adalah pengelola hotel bintang 1-5 di Kecamatan Kuta yang berjumlah 35 orang dari total populasi yaitu 71 orang dengan tingkat jabatan beragam dari tingkat manajerial seperti as. general manager dan director hingga staf pemasaran dan IT (Gambar 4.1).

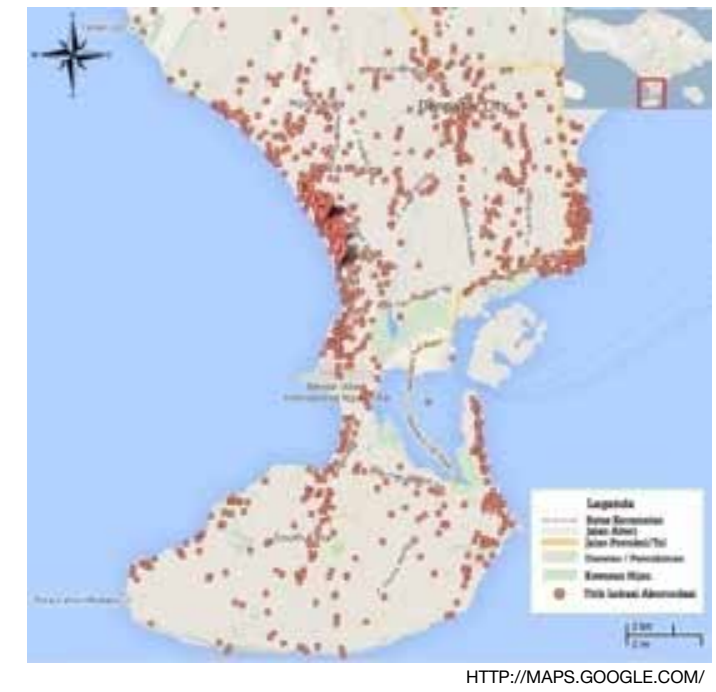

Gambar 4.1 Sebaran Usaha Akomodasi di Bali Selatan

Data hasil kuesioner kemudian dikumpulkan dan dianalisis dengan analisis faktor konfirmatori. Analisis faktor bertujuan untuk mengetahui hubungan antara indikator dengan variabel yang terbentuk. Dalam penelitian ini akan diukur satu konsep yaitu pertumbuhan usaha, dan lima konsep dari kerangka pemasaran digital yaitu attracting, engaging, retaining, learning dan relating.

\section{Pemasaran Hotel di Kecamatan Kuta Dengan Media Online}

Hotel bintang 1-5 di Kecamatan Kuta telah menggunakan media online. Setiap pengelola hotel memiliki preferensi masing-masing. Meskipun seorang pengelola hotel memiliki persepsi sebuah media online memiliki fitur untuk menjalankan kelima fungsi pemasaran digital. Pengelola hotel tersebut belum tentu memanfaatkannya. Dalam penelitian ini terdapat 19 media online yang diteliti. Berikut adalah tabel yang menunjukkan penggunaan media online dalam pemasaran hotel serta persepsi pengelola hotel terhadap fungsi yang dimiliki media online tersebut.

Berdasarkan Tabel 5.1 diketahui bahwa terdapat tujuh media online yang banyak digunakan oleh hotel bintang 1-5 di Kecamatan Kuta (dengan tanda * dan ${ }^{* *}$ ) yaitu: search engine, e-mail, website, twitter.com, facebook. com, online travel agent (OTA) dan tripadvisor.com. Rata-rata jumlah 
Tabel 5.1 Penggunaan dan Persepsi Fungsi Media Online

\begin{tabular}{|c|c|c|c|c|c|c|c|}
\hline \multirow[b]{2}{*}{ Media Online } & \multicolumn{5}{|c|}{ Fungsi Media Online } & \multicolumn{2}{|c|}{ Penggunaan } \\
\hline & Attract & Engage & Retain & Learn & Relate & $\mathrm{Ya}$ & Tidak \\
\hline 1 Search Engine * & 19 & 9 & 4 & 5 & 6 & 71 & O \\
\hline $2 E$-mail * & 12 & 15 & 9 & 7 & 15 & 67 & 4 \\
\hline 3 Website ** & 24 & 17 & 17 & 12 & 10 & 71 & o \\
\hline 4 Blog & 8 & 10 & 7 & 4 & 2 & 5 & 66 \\
\hline 5 Twitter.com * & 12 & 15 & 9 & 9 & 9 & 62 & 9 \\
\hline 6 Facebook.com ** & 20 & 21 & 12 & 12 & 14 & 69 & 2 \\
\hline 7 Plus.google.com & 11 & 12 & 6 & 7 & 9 & 52 & 19 \\
\hline 8 LinkedIn.com & 10 & 5 & 8 & 6 & 7 & 10 & 61 \\
\hline 9 Youtube.com & 14 & 8 & 5 & 4 & 4 & 32 & 39 \\
\hline 10 Flickr.com & 5 & 3 & 3 & 3 & 4 & 3 & 68 \\
\hline 11 Instagram.com & 20 & 16 & 7 & 8 & 7 & 42 & 29 \\
\hline 12 Digg & 1 & 1 & 1 & 1 & 1 & O & 71 \\
\hline 13 Reddit & 1 & 1 & 1 & 1 & 1 & O & 71 \\
\hline 14 Stumbleupon & 1 & 1 & $\mathrm{O}$ & 1 & O & O & 71 \\
\hline 15 Tripadvisor.com ${ }^{* *}$ & 25 & 20 & 19 & 18 & 14 & 70 & 1 \\
\hline 16 Online Forum & 3 & 2 & 2 & 2 & 1 & O & 71 \\
\hline 17 Virtual tour & 12 & 2 & 3 & 2 & 2 & 17 & 54 \\
\hline 18 Dunia Virtual & 4 & $\mathrm{O}$ & $\mathrm{O}$ & $\mathrm{O}$ & o & $\mathrm{O}$ & 71 \\
\hline 19 OTA $^{* *}$ & 29 & 12 & 18 & 15 & 10 & 71 & $\mathrm{O}$ \\
\hline
\end{tabular}

Sumber: Hasil Pengolahan Data, 2015

penggunaannya adalah 68,17. Search engine, website dan OTA memiliki tingkat penggunaan terbanyak karena digunakan oleh 71 hotel bintang 1-5 di Kecamatan Kuta. Hotel-hotel di Kecamatan Kuta telah memiliki website namun 14 hotel diantaranya menggunakan company group/ corporate website. 62 hotel telah menggunakan twitter.com. 69 hotel telah menggunakan facebook.com, hanya dua hotel yang tidak menggunakan facebook.com yaitu (1) Aneka Beach Hotel dan (2) Sari Segara Resort Villa and Spa. 70 hotel di Kecamatan Kuta terdata menggunakan tripadvisor.com, hanya satu hotel yang tidak menggunakan yaitu Aneka Beach Hotel.

Tabel 5.1 menunjukkan media online (tanda **) yang dinilai mampu menjalankan kelima fungsi secara seimbang adalah website, facebook. com, OTA dan tripadvisor.com. Penilaian responden terhadap media online ini hampir seimbang untuk kelima fungsi. Keempat media online ini juga merupakan media online dengan rata-rata jumlah penggunaan tertinggi. Dapat disimpulkan bahwa media online yang dinilai dapat melaksanakan beberapa atau semua fungsi pemasaran digital lebih cenderung digunakan oleh pengelola hotel.

Penggunaan media online oleh pengelola hotel berdasarkan berbagai alasan. Perkembangan teknologi khususnya smartphone menjadi salah satu 
alasan media online digunakan sebagai alat pemasaran hotel (Wawancara dengan Ni K. Yunita Liana, 5 Agustus 2015). Tujuan penggunaan media online umumnya adalah untuk menarik kunjungan secara online (attract) dan terlibat dalam interaksi di media online (engage) (Wawancara dengan Ida Ayu P. Sulitri, 3 Agustus 2015; Ni K. Yunita Liana, 5 Agustus 2015). Selain itu, media online dapat dimanfaatkan untuk branding hotel. Pengelola hotel di Kuta memilih metode mnemonic branding yaitu menggunakan nama media online yang sama dengan nama hotel. Hal ini dilakukan oleh hampir semua hotel di Kecamatan Kuta. Hal ini juga bertujuan untuk memperkuat positioning (Wawancara dengan Altaf, 5 Agustus 2015; Ida Ayu P. Sulitri, 3 Agustus 2015; Irra Agustini, 4 Agustus 2015). Media online juga dimanfaatkan sebagai alat penjualan kamar atau alat bantu reservasi kamar dalam hal ini yang dimaksud adalah OTA. Tiga OTA terbesar yang digunakan di hotel bintang 1-5 di Kecamatan Kuta yaitu agoda.com, booking.com dan expedia. com (Wawancara dengan Altaf, 5 Agustus 2015; Luh Putu Paramitha Dewi, 4 Agustus 2015).

\section{Persepsi Pengelola Hotel Terhadap Fungsi dan Fitur Media Online}

Secara rata-rata, persepsi pengelola bintang hotel 1-5 di Kecamatan Kuta terhadap fitur dan fungsi media online bernilai 4,o8. Nilai ini menunjukkan bahwa pengelola hotel setuju bahwa media online yang dilengkapi berbagai fitur bermanfaat dalam pemasaran usaha. Berdasarkan Tabel 6.1, nilai ratarata fungsi pemasaran digital tertinggi - terendah adalah attract (4.27), engage (4.22), relate (4.23), learn (3.93), dan retain (3.76). Dari 28 fitur media online yang ada, fitur yang dinilai paling bermanfaat adalah X3.1 yaitu melakukan update content secara berkala (dengan nilai 4.6), X1.2 yaitu daftar di search engine (dengan nilai 4.51) dan X2.2 yaitu content yang unik dan bermanfaat (dengan nilai 4.4). Sedangkan fitur yang dinilai paling kecil adalah X3.7 yaitu menyediakan aplikasi interaktif (dengan nilai 2.71).

Hasil analisis faktor persepsi pengelola hotel terhadap manfaat penggunaan fitur yang dimiliki media online dilakukan secara parsial untuk masing-masing fungsi media online. Pada tahap awal analisis faktor dilakukan uji KMO dan Barlett's Variabel Attract. Uji ini menggunakan batas nilai KMO MSA 0,5 dan Sig 0,05. Berdasarkan hasil perhitungan dengan SPSS v.21 yang ditunjukkan pada Tabel 6.2, nilai KMO MSA yang diperoleh untuk kelima fungsi media online lebih besar dari 0,5. Selain itu nilai Sig untuk lima fungsi media online juga lebih kecil dari 0,05. Hal ini menunjukkan asumsi untuk proses selanjutnya telah terpenuhi (Tabel 6.2).

Pemenuhan asumsi berikutnya adalah nilai MSA pada anti-image matrices di atas 0,5. Setiap indikator memiliki nilai MSA masing-masing, sehingga terdapat 28 nilai MSA. Berdasarkan perhitungan yang dilakukan dengan SPSS v.21 diketahui bahwa nilai MSA untuk semua indikator pada 
Tabel 6.1 Tingkat Persepsi Pengelola Hotel Terhadap Fitur atau Fungsi Media Online

\begin{tabular}{|c|c|c|c|}
\hline $\begin{array}{l}\text { Variabel / } \\
\text { Fungsi }\end{array}$ & Kode & Indikator / Fitur & Rata-rata \\
\hline \multirow[t]{6}{*}{ Attract } & $\mathrm{X} 1.1$ & $\begin{array}{l}\text { Menggunakan banner ads dan link website/blog anda ke media } \\
\text { online lainnya. }\end{array}$ & 4.09 \\
\hline & $\mathrm{X} 1.2$ & Mendaftarkan media online hotel di mesin pencarian. & 4.51 \\
\hline & $\mathrm{X} 1.3$ & $\begin{array}{l}\text { Menggunakan nama yang sama antara nama hotel dan setiap media } \\
\text { online yang anda gunakan (mnemonic branding). }\end{array}$ & $4 \cdot 37$ \\
\hline & $\mathrm{X} 1.4$ & $\begin{array}{l}\text { Penyediaan bandwith yang cukup untuk menampung jumlah } \\
\text { kunjungan yang besar. }\end{array}$ & 4.11 \\
\hline & $\mathrm{X} 1.5$ & Menambahkan fitur social share di website/blog. & 4.28 \\
\hline & & Rata-rata Variabel Attract & 4.27 \\
\hline \multirow[t]{7}{*}{ Engage } & $\mathrm{X} 2.1$ & $\begin{array}{l}\text { Penyediaan/pemanfaatan interactivetools seperti fitur komen di } \\
\text { media online. }\end{array}$ & 3.97 \\
\hline & $\mathrm{X} 2.2$ & Content di media online yang informatif, unik dan berguna. & 4.4 \\
\hline & $\mathrm{X} 2.3$ & Penyediaan fasilitas pemesanan online di media online. & 4.29 \\
\hline & $\mathrm{X} 2.4$ & $\begin{array}{l}\text { Membangun komunitas virtual dengan memberdayakan markom } \\
\text { (forum online, facebook group, google hangout). }\end{array}$ & 4.26 \\
\hline & $\mathrm{X} 2.5$ & $\begin{array}{l}\text { Mengadakan event melalui media online(kompetisi, kontes, lelang/ } \\
\text { sale, atau selebrasi). }\end{array}$ & 4.26 \\
\hline & $\mathrm{X} 2.6$ & $\begin{array}{l}\text { Menyediakan fitur opsi pilih bahasa di website,blogatau media } \\
\text { online lainnya. }\end{array}$ & 4.14 \\
\hline & & Rata-rata Variabel Engage & 4.22 \\
\hline \multirow[t]{8}{*}{ Retain } & $\mathbf{X}_{3.1}$ & $\begin{array}{l}\text { Melakukan update content secara berkala agar media } \\
\text { online terlihat fresh. }\end{array}$ & 4.6 \\
\hline & $\mathrm{X}_{3.2}$ & $\begin{array}{l}\text { Mengadakan program swicthing cost bagi visitor yang sering men- } \\
\text { gakses media online milik hotel. }\end{array}$ & $3 \cdot 37$ \\
\hline & $\mathrm{X}_{3 \cdot 3}$ & Menghubungkan media online dengan situs travel. & $3 \cdot 57$ \\
\hline & $\mathrm{X}_{3.4}$ & $\begin{array}{l}\text { Mengadakan program loyalty atau rewards bagi visitor atau kon- } \\
\text { sumen yang repeat order. }\end{array}$ & 4.11 \\
\hline & $\mathrm{X}_{3.5}$ & Mengurangi loading time media online milik hotel. & 3.74 \\
\hline & $\mathrm{X}_{3} .6$ & $\begin{array}{l}\text { Menyediakan sistem untuk melakukan cek / track pemesanan } \\
\text { produk/jasa/sewa kamar. }\end{array}$ & 4.2 \\
\hline & $\mathbf{X}_{3.7}$ & $\begin{array}{l}\text { Menyediakan aplikasi interaktif seperti gameonline, } \\
\text { e-postcard, e-photoframe }\end{array}$ & 2.71 \\
\hline & & Rata-rata Variabel Retain & $3 \cdot 76$ \\
\hline \multirow[t]{7}{*}{ Learn } & $\mathrm{X} 4.1$ & $\begin{array}{l}\text { Menggunakan survei, kuesioner, atau feedbackformyang dikirim } \\
\text { melalui media online. }\end{array}$ & 4.11 \\
\hline & $\mathrm{X}_{4} .2$ & $\begin{array}{l}\text { Information capture (useraccount, registration process, trip histo- } \\
\text { ry dan transaction record) dari media online. }\end{array}$ & 4.00 \\
\hline & $\mathrm{X} 4.3$ & $\begin{array}{l}\text { Online discussion di media online (virtual group) seperti new } \\
\text { product development, promotional programs. }\end{array}$ & 3.51 \\
\hline & $\mathrm{X}_{4} 4.4$ & $\begin{array}{l}\text { Memanfaatkan media online untuk mengumpulkan informasi } \\
\text { tentang calon konsumen potensial. }\end{array}$ & 4.03 \\
\hline & $\mathrm{X}_{4} \cdot 5$ & Memanfaatkan cookies untuk identifikasi IP address. & 3.91 \\
\hline & $\mathrm{X} 4.6$ & $\begin{array}{l}\text { Memanfaatkan web page tracking feature untuk mengetahui laman } \\
\text { website yang dikunjungi visitor. }\end{array}$ & 4.03 \\
\hline & & Rata-rata Variabel Learn & 3.93 \\
\hline \multirow[t]{5}{*}{ Relate } & $\mathrm{X}_{5.1}$ & $\begin{array}{l}\text { Personalisasi komunikasi saat menjawab pertanyaan dari visitor } \\
\text { media online }\end{array}$ & 4.2 \\
\hline & $\mathrm{X}_{5} .2$ & $\begin{array}{l}\text { Mengirimkan e-mail berisi informasi produk/layanan terbaru } \\
\text { kepada visitor/konsumen. }\end{array}$ & 4.2 \\
\hline & $\mathrm{X}_{5} \cdot 3$ & $\begin{array}{l}\text { Memungkinkan real time interactions misalnya berkomunikasi } \\
\text { langsung dengan sales-person. }\end{array}$ & 4.11 \\
\hline & $\mathrm{X}_{5} \cdot 4$ & $\begin{array}{l}\text { Kustomisasi tampilan media online agar lebih nyaman dan menarik } \\
\text { bagi pengunjung. }\end{array}$ & $4 \cdot 37$ \\
\hline & & $\begin{array}{r}\begin{array}{r}\text { Rata-rata Variabel Relate } \\
\text { Rata-rata Keseluruhan }\end{array} \\
\end{array}$ & $\begin{array}{l}4.23 \\
4.08\end{array}$ \\
\hline
\end{tabular}

Sumber: Hasil Pengolahan Data, 2015 
Tabel 6.2 Hasil Uji KMO dan Barlett’s Variabel Attract

\begin{tabular}{ccccc}
\hline \multirow{2}{*}{ Fungsi } & \multirow{2}{*}{ KMO MSA } & \multicolumn{3}{c}{ Bartlett's Test of Sphericity } \\
\cline { 3 - 5 } & & Approx. Chi-Square & Df & Sig. \\
\hline Attract & 0.684 & 58.671 & 10 & 0.000 \\
Engage & 0.77 & 86.322 & 15 & 0.000 \\
Retain & 0.763 & 79,097 & 21 & 0.000 \\
Learn & 0.749 & 97,270 & 15 & 0.000 \\
Relate & 0.554 & 25,397 & 6 & 0.000 \\
\hline
\end{tabular}

Sumber: Hasil Pengolahan Data, 2015

variabel attract, engage, retain, learn dan relate memiliki nilai di atas 0,5 . Selengkapnya nilai MSA ditampilkan pada tabel berikut dengan angka yamg berkode $^{\text {a }}$ (Tabel 6.3).

Tabel 6.3 Nilai MSA Pada Anti-Image Matrices

\begin{tabular}{cccccccccc}
\hline \multicolumn{2}{c}{ Attract } & \multicolumn{2}{c}{ Engage } & \multicolumn{2}{c}{ Retain } & \multicolumn{2}{c}{ Learn } & \multicolumn{2}{c}{ Relate } \\
\hline Indikator & MSA & Indikator & MSA & Indikator & MSA & Indikator & MSA & Indikator & MSA \\
\hline X1.1 & $.632^{\mathrm{a}}$ & $\mathrm{X} 2.1$ & $.695^{\mathrm{a}}$ & $\mathrm{X} 3.1$ & $.809^{\mathrm{a}}$ & $\mathrm{X} 4.1$ & $.825^{\mathrm{a}}$ & $\mathrm{X} 5.1$ & $.535^{\mathrm{a}}$ \\
$\mathrm{X} 1.2$ & $.664^{\mathrm{a}}$ & $\mathrm{X} 2.2$ & $.715^{\mathrm{a}}$ & $\mathrm{X} 3.2$ & $.759^{\mathrm{a}}$ & $\mathrm{X} 4.2$ & $.699^{\mathrm{a}}$ & $\mathrm{X} 5.2$ & $.535^{\mathrm{a}}$ \\
$\mathrm{X} 1.3$ & $.878^{\mathrm{a}}$ & $\mathrm{X} 2.3$ & $.838^{\mathrm{a}}$ & $\mathrm{X} 3.3$ & $.772^{\mathrm{a}}$ & $\mathrm{X} 4.3$ & $.641^{\mathrm{a}}$ & $\mathrm{X} 5.3$ & $.52^{\mathrm{a}}$ \\
$\mathrm{X} 1.4$ & $.658^{\mathrm{a}}$ & $\mathrm{X} 2.4$ & $.807^{\mathrm{a}}$ & $\mathrm{X} 3.4$ & $.770^{\mathrm{a}}$ & $\mathrm{X} 4.4$ & $.771^{\mathrm{a}}$ & $\mathrm{X} 5.4$ & $.738^{\mathrm{a}}$ \\
$\mathrm{X} 1.5$ & $.749^{\mathrm{a}}$ & $\mathrm{X} 2.5$ & $.894^{\mathrm{a}}$ & $\mathrm{X} 3.5$ & $.790^{\mathrm{a}}$ & $\mathrm{X} 4.5$ & $.814^{\mathrm{a}}$ & & \\
& & $\mathrm{X} 2.6$ & $.795^{\mathrm{a}}$ & $\mathrm{X} 3.6$ & $.823^{\mathrm{a}}$ & $\mathrm{X} 4.6$ & $.690^{\mathrm{a}}$ & & \\
& & & & $\mathrm{X} 3.7$ & $.645^{\mathrm{a}}$ & & & & \\
\hline
\end{tabular}

Sumber: Hasil Pengolahan Data, 2015

Output selanjutnya dari perhitungan yang dilakukan adalah nilai komunalitas tiap indikator pada masing-masing variabel. Pada tahap ini telah memasuki inti dari analisis faktor dengan menggunakan metode Principal Component dan analisis Correlation Matrix. Nilai komunalitas menunjukkan jumlah varians dari suatu indikator yang dapat dijelaskan oleh faktor yang terbentuk (Santoso, 2010: 82).

Tabel 6.4 Komunalitas

\begin{tabular}{|c|c|c|c|c|c|c|c|c|c|}
\hline & $\begin{array}{c}\text { Attract } \\
\text { Ex- } \\
\text { traction }\end{array}$ & & $\begin{array}{l}\text { Engage } \\
\text { Ex- } \\
\text { traction }\end{array}$ & & $\begin{array}{l}\text { Retain } \\
\text { Ex- } \\
\text { traction }\end{array}$ & & $\begin{array}{l}\text { Learn } \\
\text { Ex- } \\
\text { traction }\end{array}$ & & $\begin{array}{l}\text { Relate } \\
\text { Ex- } \\
\text { traction }\end{array}$ \\
\hline X1.1 & 0.707 & X2.1 & 0.606 & $\mathrm{X}_{3.1}$ & 0.723 & X4.1 & 0.535 & $\mathrm{X}_{5.1}$ & 0.806 \\
\hline $\mathrm{X} 1.2$ & 0.782 & $\mathrm{X} 2.2$ & 0.593 & $X_{3.2}$ & 0.742 & $\mathrm{X} 4.2$ & 0.726 & $X_{5.2}$ & 0.238 \\
\hline $\mathrm{X} 1.3$ & 0.311 & X2.3 & 0.439 & $\mathrm{X}_{3.3}$ & 0.614 & $\mathrm{X} 4.3$ & 0.171 & $\mathrm{X}_{5.3}$ & 0.683 \\
\hline X1.4 & 0.442 & X2.4 & 0.731 & $\mathrm{X}_{3.4}$ & 0.574 & $\mathrm{X}_{4.4}$ & 0.721 & $X_{5.4}$ & 0.205 \\
\hline \multirow[t]{3}{*}{ X1.5 } & 0.523 & X2.5 & 0.247 & $\mathrm{X}_{3.5}$ & 0.664 & $\mathrm{X} 4.5$ & 0.736 & & \\
\hline & & X2.6 & 0.672 & $\mathrm{X}_{3} .6$ & 0.409 & $\mathrm{X} 4.6$ & 0.577 & & \\
\hline & & & & $\mathrm{X}_{3.7}$ & 0.771 & & & & \\
\hline
\end{tabular}

Sumber: Hasil Pengolahan Data, 2015 
Output selanjutnya diperoleh total variance explained sebagai berikut. Untuk variabel attract hanya terbentuk satu faktor dan faktor tersebut dapat menjelaskan 55,292 persen dari variabilitas lima indikator. Untuk variabel engage hanya terbentuk satu faktor dan faktor tersebut dapat menjelaskan 54,807 persen dari variabilitas enam indikator. Untuk variabel retain terbentuk dua faktor dan secara total kedua faktor tersebut dapat menjelaskan 64,224 persen dari variabilitas tujuh indikatornya. Untuk variabel learn hanya terbentuk satu faktor dan faktor tersebut dapat menjelaskan 57,748 persen dari variabilitas enam indikator. Untuk variabel relate hanya terbentuk satu faktor dan faktor tersebut dapat menjelaskan 48,303 persen dari variabilitas empat indikator.

Setelah diketahui faktor yang terbentuk untuk masing-masing variabel, output berikutnya menunjukkan factor loadings yaitu besarnya korelasi antara indikator dengan faktor terbentuk. Semakin tinggi nilai factor loadings untuk setiap indikator, semakin besar pengaruhnya terhadap faktor yang terbentuk, demikian sebaliknya. Untuk variabel attract, X1.2 yaitu registrasi media online hotel di mesin pencarian adalah indikator dengan nilai factor loadings terbesar (o,884). Untuk variabel engage, X2.4 yaitu membangun komunitas virtual adalah indikator dengan nilai factor loadings terbesar (o,855). Untuk variabel retain, terdapat dua faktor terbentuk. Pada kelompok faktor pertama, indikator $\mathrm{X}_{3.7}$ yaitu penyediaan aplikasi interaktif adalah indikator yang memiliki nilai factor loadings terbesar $(0,878)$. Pada kelompok faktor kedua, indikator $\mathrm{X}_{3.1}$ yaitu melakukan update content secara berkala adalah indikator yang memiliki nilai factor loadings terbesar (o,850). Untuk variabel learn, X4.5 yaitu memanfaatkan cookies adalah indikator yang memiliki nilai factor loadings terbesar $(0,858)$. Untuk variabel relate, $\mathrm{X}_{5.1}$ yaitu personalisasi komunikasi adalah indikator yang memiliki nilai factor loadings terbesar $(0,898)$.

\section{Persepsi Manfaat Media Online Terhadap Pertumbuhan Usaha}

Secara rata-rata, persepsi manfaat media online terhadap pertumbuhan usaha bernilai 4,38. Nilai ini menunjukkan bahwa pengelola hotel setuju bahwa media online berpengaruh terhadap pertumbuhan usaha. Dari 4 indikator teratas pada variabel pertumbuhan usaha, 3 diantaranya adalah terkait dengan branding. Hal ini menunjukkan bahwa pemasaran dengan media online dinilai lebih berdampak langsung pada branding.

Analisis faktor persepsi manfaat media online terhadap pertumbuhan usaha juga dilakukan. Nilai KMO MSA yang diperoleh untuk variabel pertumbuhan usaha lebih besar dari o,5 yaitu o,696. Selain itu nilai Sig untuk variabel pertumbuhan usaha lebih kecil dari o,05 yaitu o,ooo. Pemenuhan asumsi berikutnya adalah nilai MSA pada anti-image matrices di atas 0,5. 
Tabel 7.1 Tingkat Persepsi Manfaat Media Online Terhadap Pertumbuhan Usaha

\begin{tabular}{cclc}
\hline Variabel & Kode & \multicolumn{1}{c}{ Indikator } & Rata-Rata \\
\hline & Y.1 & Brand awareness & 4.63 \\
& Y.2 & Brand identity & 4.40 \\
& Y.3 & Brand loyalty & 4.40 \\
Pertumbuhan Usaha & Y.4 & Peningkatan market share & 4.34 \\
& Y.5 & Peningkatan ROI & 4.09 \\
& Y.6 & Peningkatan Pendapatan Perusahaan & 4.40 \\
& Y.7 & Peningkatan Jumlah Visitor Media Online & 4.43 \\
& Y.8 & Peningkatan Jumlah Visitor yang Menginap & 4.34 \\
\hline
\end{tabular}

Sumber: Hasil Pengolahan Data, 2015

Berdasarkan perhitungan yang dilakukan diketahui bahwa nilai MSA untuk semua indikator pada variabel pertumbuhan usaha memiliki nilai di atas 0,5. Hal ini menunjukkan asumsi-asumsi yang diperlukan untuk proses selanjutnya telah terpenuhi.

Pada tahap ini telah memasuki inti dari analisis faktor. Output pertama yang dihasilkan adalah komunalitas. Berdasarkan perhitungan diperoleh nilai komunalitas untuk masing-masing indikator yaitu komunalitas Y.1 = 0,681; komunalitas Y.2 = 0,829; komunalitas Y.3 = 0,654; komunalitas Y.4 $=0,291$; komunalitas Y.5 = 0,672; komunalitas Y.6 = 0,847; komunalitas Y.7 $=0,569$; komunalitas Y.8 = 0,766. Semakin besar nilai komunalitas berarti semakin erat hubungannya dengan faktoryang terbentuk (Santoso, 2010: 82). Output selanjutnya adalah total variance explained. Dari hasil perhitungan diperoleh dua faktor terbentuk dan secara total kedua faktor tersebut dapat menjelaskan 66,375 persen dari variabilitas delapan indikatornya. Setelah diketahui dua faktor terbentuk, output berikutnya menunjukkan factor loadings. Pada kelompok faktor pertama secara berurutan nilai factor loadings untuk kelima indikator adalah Y.4 (0,524), Y.5 (o,802), Y.6 (o,879), Y.7 (0,566) dan Y.8 (o,818). Pada kelompok faktor kedua secara berurutan nilai factor loadings untuk ketiga indikator adalah Y.1 (o,748),Y.2 (o,888), dan Y.3 (0,790). Y.2 merupakan indikator yang mendapatkan manfaat terbesar dari penggunaan media online.

Berdasarkan penelitian ini dapat diketahui bahwa media online yang dilengkapi berbagai fitur dan memiliki kemampuan menjalankan lima fungsi pemasaran digital merupakan alat pemasaran usaha yang semakin dipertimbangkan untuk digunakan oleh pengelola hotel di Kecamatan Kuta. Jika pengelola hotel mampu mengikuti memanfaatkan fitur-fitur X1.2 untuk attract, x2.4 untuk engage, x3.1 untuk retain, x4.5 untuk learn, dan x5.1 untuk relate maka diharapkan akan berpengaruh pada pertumbuhan usaha tidak hanya branding namun juga profitabilitas. 


\section{Penutup}

Berdasarkan uraian di atas diketahui terdapat tujuh media online yang banyak digunakan yaitu: search engine, e-mail, website, twitter.com, facebook.com, online travel agent (OTA) dan tripadvisor.com. Semakin banyak fungsi pemasaran digital (attract, engage, retain, learn dan relate) yang mampu dihasilkan oleh media online semakin besar kecenderungan untuk digunakan. Empat media online yang dinilai relatif seimbang dalam melaksanakan lima fungsi pemasaran digital adalah website, facebook.com, OTA dan tripadvisor.com.

Berdasarkan perhitungan rata-rata persepsi responden diperoleh nilai 4,08. Hal ini berarti fitur-fitur yang dimiliki media online dinilai bermanfaat dalam menghasilkan fungsi pemasaran digital. Fitur yang dianggap paling bermanfaat adalah update content secara berkala (4.60), pendaftaran media online hotel di search engine $(4,51)$, dan membuat konten yang unik (4.40). Berdasarkan analisis faktor, setiap fitur memiliki besar manfaat yang berbeda-beda terhadap fungsi pemasaran digital. Fitur dianggap paling membantu adalah X1.2 yaitu pendaftaran media online di search engine (untuk fungsi attract), X2.4 yaitu membangun komunitas virtual (untuk fungsi engage), X4.5 yaitu menggunakan cookies untuk mengidentifikasi alamat IP (untuk fungsi learn), X5.1 yaitu komunikasi pribadi (untuk fungsi relate). Fitur dianggap paling bermanfaat untuk mempertahankan (relate) adalah $\mathrm{X}_{3.7}$ yaitu aplikasi interaktif dan $\mathrm{X}_{3.1}$ yaitu memperbarui content secara teratur.

Pengelola hotel harus memanfaatkan media online sebagai alat pemasaran. Maka harus dipersiapkan anggaran khusus untuk pemasaran online disamping pemasaran konvensional serta staf khusus yang menangani media online milik hotel karena perkembangan media online yang sangat cepat. Perkembangan media online yang digunakan calon konsumen (wisatawan) harus tetap diperhatikan pengelola hotel agar media online yang dipilih untuk melakukan pemasaran tepat dengan pasar. Oleh karena itu, pengelola pemasaran perlu mempertimbangkan dan mempelajari secara berkelanjutan media online serta memperhatikan fungsi-fungsi pemasaran digital yang ingin dicapai.

\section{Ucapan Terima Kasih}

Ucapan terima kasih disampaikan kepada Prof. Dr. I Ketut Sudibia, SU sebagai Pembimbing 1, serta untuk Bapak Dr. I Nyoman Madiun, M.Sc. (almarhum) sebagai Pembimbing 2, atas masukan dan saran yang diberikan dan sangat membantu penulis dalam penyelesaian penelitian ini. Terima kasih diucapkan kepada Ida Ayu P. Sulitri, Luh Putu Paramitha Dewi, Irra Agustini, Ni K. Yunita Liana, dan Bapak Altaf atas kesediaannya memberikan informasi penting terkait penelitian ini. Selain itu, terima 
kasih juga diucapkan kepada 35 responden atas kesediaannya mendukung pengumpulan data kuesioner penelitian ini.

\section{Daftar Pustaka}

UNWTO. 2015. Tourism Highlights 2015 Edition. Madrid: UNWTO

Singapore Tourism Board. 2013. Navigating The Next Phase of Asia's Tourism. Singapore: Singapore Tourism Board

Tim Penyusun. 2016. Direktori 2015. Denpasar: Dinas Pariwisata Provinsi Bali.

Robbins, S.P. dan Judge, T.A.. 2013. Organizational Behavior $15^{\text {th }}$ Edition.New Jersey: Pearson Education Inc.

Kierzkowski A., McQuade S., Waitman R., dan Zeisser M.. Marketing To The Digital Consumer. The McKinsey Quarterly1996 No. 3. 1996. McKinsey \& Company p.5-21

Picard, Michel. 2006. Bali: Pariwisata Budaya dan Budaya Pariwisata. Terjemahan oleh Kepusatakaan Populer Gramedia dari Bali: Tourisme Culturel et Culture Touristique. Jakarta: Kepustakaan Populer Gramedia

Kotler, Bowen, Makens. 2010. Marketing for Hospitality and Tourism 5th ed. New Jersey: Pearson Prentice Hall

Zarrella, Dan. 2010. The Social Media Marketing Book. Canada: O’Reilly.

Yoeti, Oka A. 1999. Strategi Pemasaran Hotel. Jakarta: PT Gramedia Pustaka Utama Teo, T.S.H., dan Tan, J.S.. 2002. Senior Executives' Perceptions Of BusinessTo-Consumer (B2C) Online Marketing Strategies: The Case Of Singapore. Singapura: National University of Singapore

Santoso, Singgih. 2010. Statistik Multivariat: Konsep dan Aplikasi dengan SPSS. Jakarta: PT Elex Media Komputindo

\section{Profil Penulis}

Bagus Putu Wahyu Nirmala adalah alumnus Program Magister (S2) Kajian Pariwisata Program Pascasarjana Universitas Udayana. Ia menyelesaikan pendidikan Sarjana Strata I di Program Studi Teknik Industri, Institut Teknologi Bandung. Tahun 20112013 menjabat sebagai Asisten Koordinator Sekretariat di Bali Tourism Board (BTB) atau Gabungan Industri Pariwisata Indonesia (GIPI) Bali. Saat ini ia bertugas sebagai Tenaga Pengajar dan menjabat Kepala Inkubator Bisnis di Sekolah Tinggi Manajemen Informatika dan Komputer (STMIK) Primakara, Denpasar. Di institusi yang sama ia aktif sebagai peneliti bidang e-tourism (electronic tourism) - penerapan teknologi informatika dan komputer untuk pariwisata. E-mail: bagus.p.wahyu@gmail.com 